\title{
Information Technology Driven Curriculum Design for Optimized Chemical Engineering Education
}

\author{
Kuyen Li, John Gossage, and David Cocke \\ Chemical Engineering Department \\ Lamar University, Beaumont, Texas 77710
}

\begin{abstract}
The Lamar Chemical Engineering Department is conducting a study to redesign the curriculum that will: a) integrate information technology into chemical engineering education, b) serve as a problem-based learning approach to the fundamental content of chemical engineering, and c) develop computer skills with modeling and simulation packages that the student will need in the co-op program with industry and in all subsequent chemical engineering courses. A pathfinder course, Computer Aided Modeling and Simulation (CAMS), links problem-based learning goals to existing computer modeling and simulation packages with interactive examples that introduce the students to fundamental principles in Kinetics, Thermodynamics, Momentum Transfer, Heat Transfer, Mass Transfer, Process Control and Plant Design. This Pathfinder Course converges to a senior year capstone course - Advanced Analysis. The prototype educational materials, designed to maximize the utilization of computer modeling and simulation packages for constructivist student learning, are being tested for student performance in subsequent courses and co-op experiences. The pedagogical theory of learning based on constructivism is being utilized in the work capitalizing on the authors' experience with problem-based learning.
\end{abstract}

\section{Introduction}

"Information Technology" as used here simply means the methods for knowledge transfer. Knowledge will not be useful unless it can be transferred to the right person at the right time. Knowledge transfer is information.

A traditional chemical engineering curriculum lays out courses that give a solid foundation of basic knowledge in chemical engineering, but the connections among the courses are poor. This paper will explore a curriculum redesign in chemical engineering education based on the knowledge transfer (or information technology) concept.

With the increasing computer literacy among undergraduate students, the most effective way to transfer knowledge to them is by using a computer or computer system. A computer can do not only computations but also make logical decisions and transfer data (or information). From experience, we all agree that the usage of computer software is important in engineering education. Now, we have to integrate this implementation in the curriculum to best effect.

The Lamar Chemical Engineering Department is conducting a proof-of-concept study to 
redesign the curriculum using a new multifaceted course that will: a) integrate information technology into chemical engineering education, b) serve as a problem-based doorway to the fundamental content of chemical engineering, and c) develop computer skills with modeling and simulation packages that the students will need in the co-op program with industry and in all subsequent chemical engineering courses.

\section{Computer-Aided Modeling and Simulation (CAMS) - A Pathfinder Course}

In 1999, the authors along with their colleagues received a Nation Science Foundation CCLI-A\&I (Course, Curriculum, and Laboratory Improvement - Adaptation and Implementation) grant. This led to the initiation of a prototype course to integrate problembased learning (PBL) pedagogy into the chemical engineering curriculum by use of computer-aided modeling and simulation packages. It starts with a new course, CAMS (Computer Aided Modeling and Simulation), in the sophomore level and concludes at a senior course of Advanced Analysis. The course structure can be seen in Figure 1.

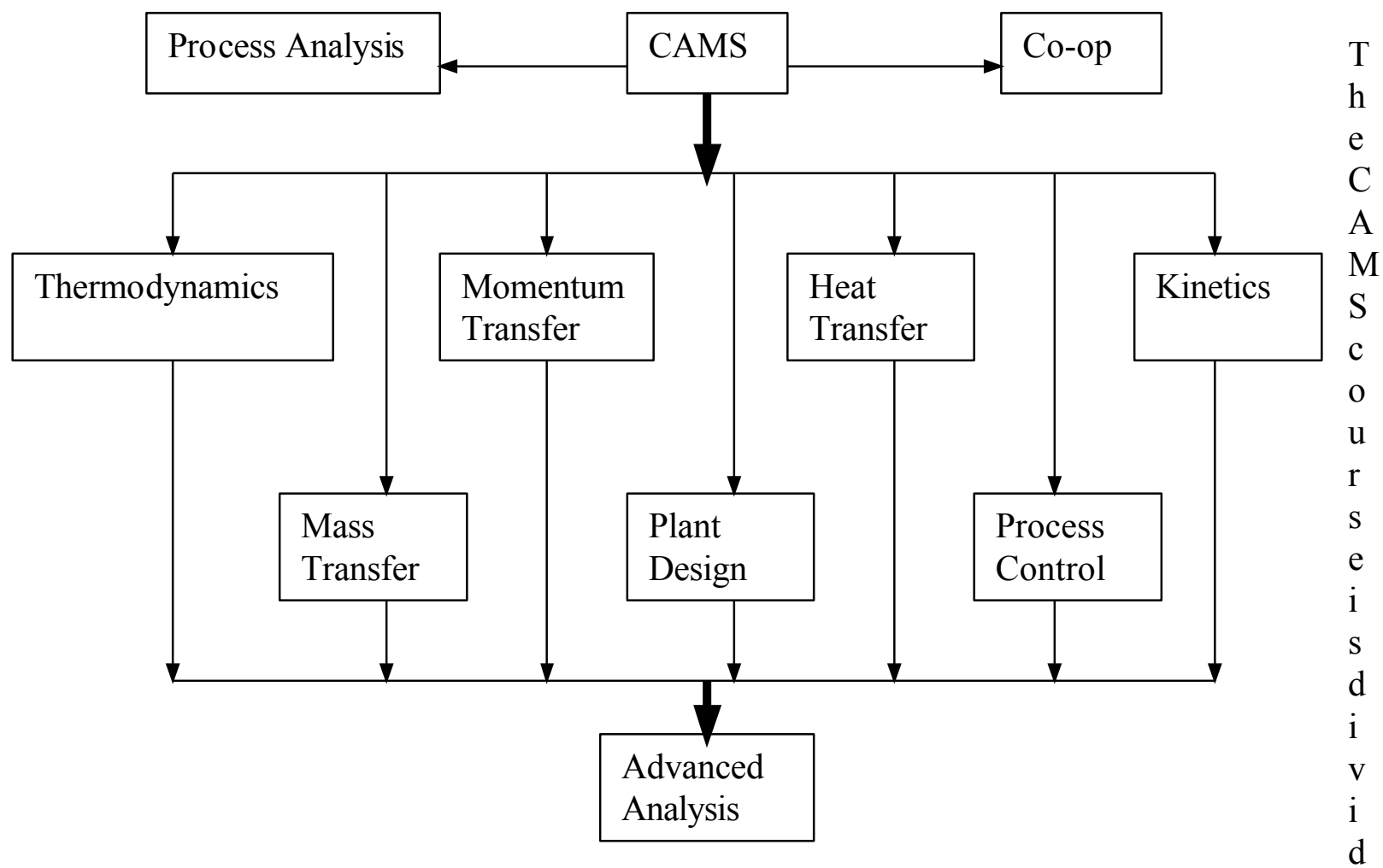

ed into two parts. During the first part of the semester (generally the first five or six weeks), the students are exposed to two mathematical software packages: POLYMATH and Mathcad. They use these programs to solve typical engineering mathematics problems such as numerical integration (including shooting problems), solution of nonlinear equations, and both linear and nonlinear regression. These mathematical tools are extremely useful to the students, especially as they move into their upper-level engineering courses.

The second part of the semester (about the last nine or ten weeks) is devoted to the use of 
two simulation packages: Aspen and Pro/II. Since the students take this class and the Process Analysis (or Material and Energy Balances, as it is frequently called at other schools) class simultaneously, they generally begin the semester with little or no understanding of basic chemical engineering concepts. Thus, in addition to learning the "nuts and bolts" of using the simulation packages, they also must learn at least the rudiments of such common unit operations as heat exchangers, reactors, flash drums, and distillation columns. Of course, at this level the students are asked to accept some of the information (such as the governing equations) "on faith", with the promise that the details will be covered in subsequent chemical engineering classes such as Heat Transfer, Kinetics, Chemical Engineering Thermodynamics, and Mass Transfer. In this sense, the CAMS course acts as a "pathfinder" course, since it sets the stage for all the succeeding chemical engineering courses that the students will see in their academic careers.

At the other end of their undergraduate academic career, the students encounter the seniorlevel Advanced Analysis (AA) class, in which problem-based learning is used to tie together all of the material that the students have learned in all of their chemical engineering courses between CAMS and AA.

Two additional topics are covered during the second part of the semester of CAMS. The solution methods employed by the simulation packages are discussed in a general way, so that the students can understand how the packages work (and, occasionally, don't work) [Felder and Rousseau, 2000]. Finally, selection of the correct thermodynamics package for a given problem is also discussed [Carlson, 1996], because selecting an inappropriate thermodynamics package usually leads to incorrect simulation results.

One unexpected benefit of this class has been its value to the students in the co-operative education (co-op) program. Students who have co-oped after taking CAMS report that they have frequently used the simulation experience they gained in CAMS "on the job". In effect, their co-op experience is problem-based learning, since they are working on openended, practical, ill-defined problems that require creativity to solve.

To teach Computer Aided Modeling and Simulation at a stage as early as the sophomore year is quite new in the chemical engineering curriculum. Nevertheless, after two years of experience, this approach leads to obvious advantages.

The first advantage is to help the students in co-op program and in the Process Analysis (Material and Energy Balance) course. Most of our co-op students use one of the simulation packages (such as ASPEN, Pro/II, HYSYS, or WinSim) during their co-op terms. CAMS prepares them early enough that they are able to move into the working situation quickly to solve practical problems in industry. When the co-op students come back to school to learn the fundamental principles in junior/senior engineering basic courses, they already have this "problem based learning" pedagogical mind-set. This helps to pave the way for "problem based learning" pedagogy in the upper-level chemical engineering curriculum. 
The NSF-CCLI implementation project has found that the co-op students can learn the fundamental principles more effectively than the non-co-op students. This could be a difference between the learning pedagogies of science and engineering education. In other words, the engineering students see the advantages of learning fundamental principles to solve problems.

The other advantage of CAMS is to prepare the students for the chemical engineering sophomore (Process Analysis), junior (Thermodynamics, Momentum Transfer, Heat Transfer, and Kinetics) and senior (Mass Transfer, Plant Design, and Process Control) courses in problem based learning with an implementation of computer aided modeling and simulation. CAMS teaches the students to do process simulations using such units as mixers, separators, heat exchangers, columns, reactors, and pressure changers. These units are the applications of Process Analysis, Momentum Transfer, Heat Transfer, Mass Transfer, and Kinetics. In addition, the selection of the thermodynamic models prepares the students to learn about non-ideal mixtures of chemical compounds that will be studied in Thermodynamics. Finally, CAMS helps the students prepare for both Process Control courses as follows. In the Process Control courses, the students learn to use dynamic simulation (in particular, DMC, or Dynamic Matrix Controller). However, the first step in performing a dynamic simulation is to perform the steady-state simulation. This, the students learn in CAMS. Thus, CAMS serves as a pathfinder course in the chemical engineering curriculum.

\section{Advanced Analysis - A Capstone Course}

Finally, in a last semester senior course, Advanced Analysis, the CCLI laboratory is used fully to implement the CAMS and the problem based learning pedagogy. In Advanced Analysis, chemical engineering problems are given to the students at least one week ahead for the students to study. In the class, students have to use the fundamental principles learned from the preceding courses (shown in Figure 1) to set up the system equations or the inputs for the CAMS packages. The instructor may initiate the questions and when the students answer the questions the others may challenge those answers. The instructor may give minimum necessary corrections to facilitate the discussion. Through this problem based learning pedagogy, students can concentrate more than in a traditional teaching method because of the participation.

To use the PBL pedagogy fully, a description of the problem must be distributed to the students days or even one week before the class discussion. This gives time for the students to understand the problem, search for references, and prepare for the class discussion. Examples are given below:

1) Flash vaporization: The problem given in the class is an equilibrium flash vaporization.

A feed stream flowing at 1000 $\mathrm{lb} / \mathrm{hr}$ contains an equimolar mixture of n-butane, npentane, n-hexane, and n-

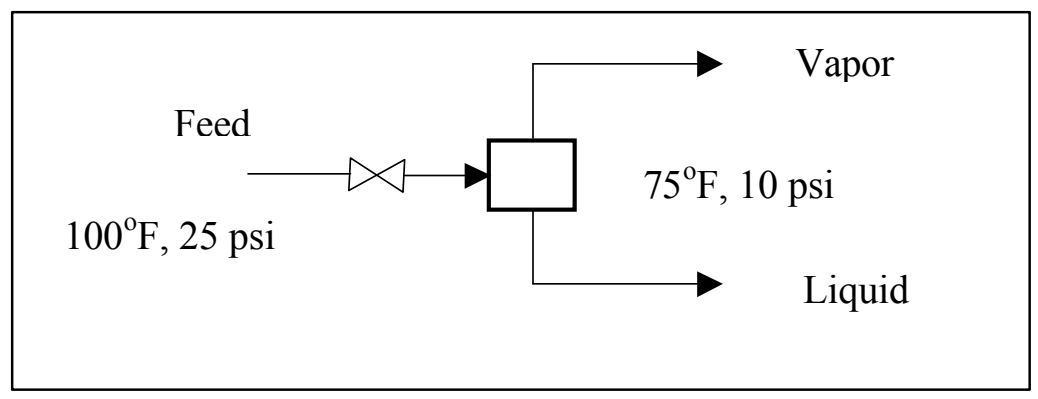


heptane at $100^{\circ} \mathrm{F}, 25 \mathrm{psi}$. The feed enters a flash drum maintained at $75^{\circ} \mathrm{F}$ and $10 \mathrm{psi}$. What is the flow rate and composition of the vapor and liquid streams leaving the flash drum?

What students can discuss from this problem are (1) equilibrium versus non-equilibrium flash vaporization, (2) isothermal versus adiabatic flash vaporization, and (3) pre-heat versus reduce pressure flash vaporization. Students are encouraged to participate in the discussion and modeling of the system.

The CCLI Laboratory is equipped with four electronic white boards connected to computers. These boards can be used to save the written information on the computers' hard drives. Because of the electronic boards, the students do not have to worry about taking notes. Instead, they can concentrate on the discussion of the modeling process. The instructor gives only guidance but not the "solution". Both sides of an assumption should be explored and discussed, and a reasonable assumption can be recognized but not assigned. Because of participation, the students have better understanding of the problem than they would achieve in the traditional one-way lecture.

To solve the system equations, we show briefly the algorithm and an old computer program written in BASIC to take the input and calculate the converged solution output. Then, we ask the students to use ASPEN or Pro/II to work on the same problem. Although they have learned the package in the sophomore CAMS course, now they can appreciate how well the simulation package works. But this is not the end. The class also takes advantage of the simulation package to explore the effects of changing process variables. The instructor will enjoy the presentation of the results. Be prepared for the discussions.

The students can present their results through a computer network with the LCD projector. Now, again, the interpretation is open to discussion. For this example, the effects are simple: more lighter compounds will be vaporized if low drum pressure or a feed pre-heater is used. For other more-complicated systems, the discussions of the results are quite involved. Most of the students find that it is very helpful to understand the system behavior through discussion of the results. This part is called the interpretation of the results.

2) Safety Analysis: Another part of the Advanced Analysis class is safety case studies. The class is separated into groups to analyze case studies such as the following:

1. Piper Alpha - Spiral to Disaster

2. Phillips 66 Company Explosion and Fire at Pasadena, Texas

3. Methacrylic Acid Tankcar Explosion and Methods of Safety Handling

These cases are from the Safety and Chemical Engineering Education (SAChE) Division of the American Institute of Chemical Engineers (AIChE). 
The materials including video and CD are distributed to the group one week before the group discussion. The students watch the video/CD, discuss the events that occurred, collect the information, and then analyze the safety considerations. The students use the electronic boards for group discussion. The instructor monitors the group discussion from the instructor's station but does not interrupt their discussions. All the group discussion material is saved into the computer without typing. The students are totally free from typing or note-taking so that their group discussion is very involved. We find this type of "problem-based" and "student-centered" discussion and learning are very effective. Every student is challenged to participate and contribute to the problem solving.

\section{Conclusion}

A change from instructor-centered to student-centered, computer aided PBL learning in higher education poses challenges for administrators, educators, students and classroom designers. Computer based PBL courses must be carefully designed to meet the pedagogical objectives. In the case of computer-aided PBL, the course material and the modern electronic classroom are essential for optimization of the PBL process.

\section{Acknowledgment}

This work has been supported by CCLI grant \#9981152 from the National Science Foundation entitled "Integrating Best Practice Pedagogy with Computer-Aided Modeling and Simulation to Improve Undergraduate Chemical Engineering Education”.

\section{References}

Carlson, Eric C., "Don't Gamble With Physical Properties For Simulations", Chemical Engineering Progress, October 1996, pgs. 35-46.

Felder, Richard M., and Ronald W. Rousseau, Elementary Principles of Chemical Processes 3rd Edition, John Wiley \& Sons, 2000, Chapter 10. 